\title{
Intestinal microflora and gastrointestinal adaptation in the rat in response to non-digestible dietary polysaccharides
}

\author{
BY G. M. WYATT, N. HORN, J. M. GEE AND I. T. JOHNSON \\ AFRC Institute of Food Research, Norwich Laboratory, Colney Lane, Norwich NR4 $7 U A$
}

(Received 3 December 1987 - Accepted 29 March 1988)

\begin{abstract}
1. A comparison was made of the effect of a fibre-free diet and diets containing non-digestible polysaccharides on rat caecal and colonic physiology and microflora.

2. All polysaccharide-containing diets led to enlargement of the caecum and colon, associated with increased weight of contents, and of tissue. Carboxymethylcellulose (CMC) had the most marked effect and animals given this also had watery faeces.

3. The density of bacteria in the caecum and colon varied significantly with diet and the proportion of aerobic bacteria in the flora was increased by the CMC diet.

4. In vitro, CMC and hydroxypropylmethylcellulose were poorly fermented.

5. There was a high correlation (caecum r 0.93; colon $r 0.94$ ) between tissue weight and wet weight of organ contents but no correlation with bacterial density, number of bacteria per organ, moisture content or short-chain fatty acid content.

6. It is concluded that caecal and colonic enlargement is due to tissue hypertrophy in response to increased bulk of contents, irrespective of the nature of that bulk which varies with diet; it is unlikely that short-chain fatty acids or other microbial metabolites are the stimulus for the trophic response seen when non-digestible dietary polysaccharides are fed to rats.
\end{abstract}

It is well established that non-digestible components of the diet (that is, not digested by mammalian enzymes) influence the growth and function of the gastrointestinal organs in laboratory animals (Leegwater et al. 1974; Wang, 1979; Elsenhans et al. 1981; Rowland \& Walker, 1983; Konishi et al. 1984). The hypertrophic effect of carbohydrate polymers on the rat caecum is very much more marked than that of equivalent quantities of inert bulking materials such as kaolin (Dowling et al. 1967; Sakata, 1986). A number of hypotheses have emerged to explain this difference. El Harith et al. $(1976,1977)$ suggested that the caecal enlargement in response to raw starch was an adaptive response resulting from changes in the caecal microflora. Similar conclusions were reached by Elsenhans et al. (1981) and Jacobs \& Lupton (1984) who reported that fermentable polysaccharides gave rise to greater caecal enlargement than non-degradable polymers. These observations seem consistent with recent reports by Sakata $(1986,1987)$ showing that short-chain fatty acids (SCFA), which are important microbial breakdown products of carbohydrates, stimulate epithelial cell production and lead to increased mucosal growth. In contrast, however, Konishi et al. (1984) reported that the initial response of the rat caecum to a diet containing glucomannan was cellular hypertrophy rather than increased cell proliferation, and they suggested that the important stimulus was the physical suppression of water absorption by the hydrophilic polymer in the bowel lumen. Recently, Johnson \& Gee (1986) described the growth and cytokinetics of intestinal tissues in rats fed on diets containing insoluble microcrystalline cellulose, the soluble derivative (carboxymethylcellulose; CMC), or guar gum. Despite the ready susceptibility of guar gum to fermentation by the caecal microflora (Horn et al. 1986), CMC gave rise to greater enlargement of the caecum and a more marked enhancement of mucosal cell proliferation than guar gum. The purpose of the present study was to explore in more detail the relation between the microbial breakdown of dietary polysaccharides and the adaptive response of both the microflora and the tissues of the large bowel in the rat. 
MATERIALS AND METHODS

\section{Animals}

Male Wistar rats (130-200 g) were obtained from a commercial supplier and randomly allocated to test groups of five animals each, housed in wire-bottomed cages. All groups received feed and water ad lib., and each was given the basal fibre-free diet for $5 \mathrm{~d}$ before changing to the test diets. The feeding period was $12 \mathrm{~d}$ unless otherwise indicated.

\section{Diets}

The composition of the basal fibre-free diet was $(\mathrm{g} / \mathrm{kg}$ diet): starch (Snoflake maize flour; Corn Products Ltd, Manchester) 360, sucrose 300, casein (edible casein; Glaxo Farley Foods, Plymouth) 200, maize oil 80, mineral mix (Johnson et al. 1984) 40 and vitamin mix (Johnson et al. 1984) 20. In the test diets, the polysaccharides hydroxypropylmethylcellulose (HPMC; Courtaulds Chemicals \& Plastics, Derby), CMC (BDH, Poole, Dorset), and carboxymethyl guar (CMG; Meyhall Chemical AG, Merseyside) replaced 100 g sucrose/ $\mathrm{kg}$. Diarrhoea was induced in one group by feeding a diet in which magnesium sulphate replaced $40 \mathrm{~g}$ sucrose $/ \mathrm{kg}$.

In one experiment cellulose (SF; 'Solkafloc', Johnson Jorgensen Wettre, London) replaced $100 \mathrm{~g}$ sucrose/ $\mathrm{kg}$ and guar gum (Sigma Chemical Co., Poole, Dorset) replaced $40 \mathrm{~g}$ sucrose $/ \mathrm{kg}$; both were given for $7 \mathrm{~d}$.

\section{Experimental procedure}

Animals were housed in a room having a $12 \mathrm{~h}$ light- $12 \mathrm{~h}$ dark cycle, and experiments were carried out in the morning. At the end of the feeding period the animals were anaesthetized by intraperitoneal injection (Euthetal, May \& Baker, Dagenham; $1 \mathrm{ml} / \mathrm{kg}$ body-weight) and killed by cervical dislocation. The abdomen was opened and the caecum and ascending colon were separately ligatured, removed and weighed. The caecum was transferred to an anaerobic cabinet containing an atmosphere of nitrogen-hydrogen-carbon dioxide (85:10:5, by vol.) where it was opened, and samples of contents were reserved for weighing and subsequent drying to constant weight at $105^{\circ}$. A slurry was then made from a known weight (approximately $1 \mathrm{~g}$ ) of contents in $9 \mathrm{ml}$ of anaerobic dilution solution (ADS; Bryant $\&$ Burkey, 1953) for enumeration of anaerobes and aerobes on plates of complex growth media as previously described (Horn et al. 1986). The contents of the colon were squeezed out under a stream of $\mathrm{O}_{2}$-free $\mathrm{CO}_{2}$ and similarly treated. Caecal and colonic tissues were gently rinsed under running water, blotted dry and weighed, and then oven-dried to constant weight. A portion of caecal contents was frozen for subsequent analysis of SCFA by the method of Bayliss \& Houston (1985).

Characterization of aerobic bacteria. All the colonies (minimum twenty) on the plates from the highest dilution were examined. Preliminary identification was made from colony morphology on the isolation medium (CLED agar; Oxoid Ltd) and confirmed by using either the AP120E system (API Laboratory Products, Basingstoke) or the methods of Cowan (1974).

Toxin testing of Escherichia coli strains. A Vero cell enterotoxin activity assay was used which detects both heat-labile enterotoxin and Vero cytotoxin (Scotland et al. 1985). Additionally, because Vero cells do not respond to heat-stable enterotoxin, serotyping of cultures was carried out.

Analysis of carbohydrate in intestinal contents of $C M C$-fed rats. To determine the amount of CMC present, residual starch in the ileal and colonic contents of rats fed on the CMC diet for $7 \mathrm{~d}$ was first removed by a modification of the method of Faulks \& Timms (1985). Contents were dried over phosphorus pentoxide and ground to a fine powder; $20 \mathrm{mg}$ were dispersed in $1 \mathrm{ml}$ dimethyl sulphoxide and heated for $5 \mathrm{~min}$ at $100^{\circ}$. Starch was hydrolysed 
by incubating this sample at $37^{\circ}$ for $1 \mathrm{~h}$ with amyloglucosidase (EC $3.2 .1 .3 ; 65$ units) and $\alpha$-amylase (EC 3.2.1.1; 1120 units) (Sigma Chemical Co.) in $8 \mathrm{ml}$ acetate buffer, $\mathrm{pH} 4 \cdot 6$. The remaining polysaccharide in the destarched material was precipitated by treatment with ethanol $(900 \mathrm{ml} / 1$ final concentration). After centrifugation the precipitate was washed with ethanol $(900 \mathrm{ml} / 1)$ and redissolved in distilled water; total carbohydrate in this solution was measured by the phenol-sulphuric acid method of Dubois et al. (1956). using glucose as a standard. As a measure of the extent of degradation of the CMC polymer a reducing-end assay (Dygert et al. 1965) was compared with a similar assay on the contents from animals fed on the fibre-free diet.

Intracaecal $p H$ changes. In a separate experiment three groups of five rats were fed for $28 \mathrm{~d}$ on test-diets containing Solkafloc, CMC or guar gum at a level of $100 \mathrm{~g} / \mathrm{kg}$ diet. At the end of this period the animals were killed as described above. The caecae were exposed immediately and opened at the caeco-colonic junction and the $\mathrm{pH}$ of the caecal contents was measured using a semi-micro pH-electrode as described by Southon et al. (1987).

Faecal output. The effects of the test materials on the faecal outputs of rats were assessed in a separate study. After the $12 \mathrm{~d}$ feeding period a complete $24 \mathrm{~h}$ faecal collection was made from groups of five animals as described. Where possible, discrete faecal pellets were separated from spilled food and weighed. Unformed faecal material was collected on preweighed paper sheets, oven-dried and re-weighed. In all cases the wet weight was determined from freshly voided material.

In vitro fermentation of polysaccharides. All media were pre-reduced and prepared using the techniques of Hungate (1969); complete anaerobiosis was maintained during subsequent manipulations by the use of the anaerobic cabinet. Utilization of guar gum, CMC, CMG, HPMC and SF was tested in the complex medium SM10 (Barnes \& Impey, 1974) without glucose, cellobiose or starch (BSM10). Test substrates $(2.0 \mathrm{mg} / \mathrm{ml})$ were added aseptically to $150 \mathrm{ml}$ BSM10 in 250-ml batch culture vessels using the anaerobic cabinet and dissolved or dispersed by stirring overnight at $2^{\circ}$. Broths were prewarmed to $37^{\circ}$ before inoculation. Slurries of caecal contents from rats fed on the fibre-free diet were prepared in anaerobic dilution solution, as described previously. A $1.5 \mathrm{ml}$ portion of slurry was used to inoculate $150 \mathrm{ml}$ broth; the culture vessels were incubated at $37^{\circ}$ using a shaking platform.

Total viable bacterial counts were estimated after $0,6,12,24$ and $48 \mathrm{~h}$ of incubation of the batch cultures. For each sample a tenfold dilution series in ADS was prepared and viable bacteria enumerated, after $7 \mathrm{~d}$ incubation at $37^{\circ}$, on plates of a complex medium (VLhlf) as described by Horn et al. (1986). Carbohydrate utilization was determined using the phenol-sulphuric acid method of Dubois et al. (1956); concentrations were read from standard curves prepared with either the polysaccharide or glucose. Samples of the batch cultures were taken after $0,6,12,24,48 \mathrm{~h}$ and $7 \mathrm{~d}$ of incubation. Free reducing-ends in the culture fluids of HPMC, CMG and CMC fermentations were determined by the method of Dygert et al. (1965).

Water-holding capacity (WHC) determination. The WHC of CMC, CMG, HPMC and SF was determined by the method of McBurney et al. (1985). An osmotic suction pressure of $89 \mathrm{mosmol} / 1$ (2 atm) was used for all measurements. Samples $(100 \mathrm{mg})$ were first dissolved or dispersed in $5 \mathrm{ml}$ sodium azide solution $(1 \mathrm{mg} / \mathrm{ml})$ to hydrate the sample.

\section{Statistical analysis}

Analysis was performed using the computerized statistical package MINITAB (Pennsylvania State University). Significance of differences between means was tested using a $t$ procedure for independent samples. When required, simple regression lines or, where indicated by residual analysis, polynomial regression lines were fitted to values. 
200

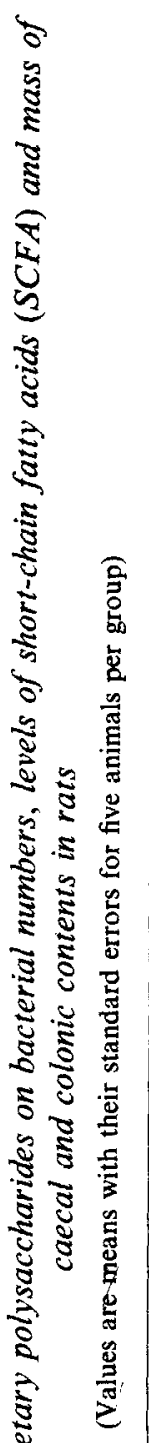

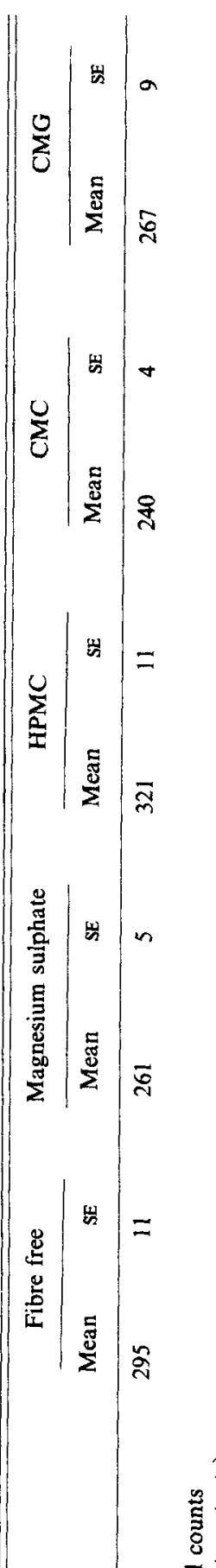

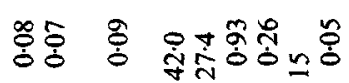

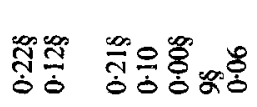

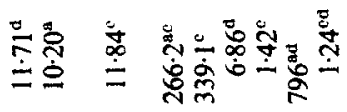

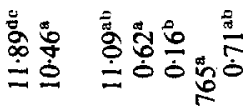

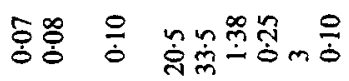

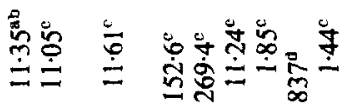

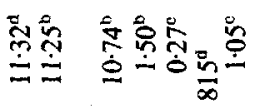

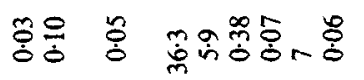

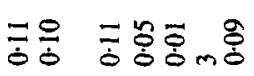

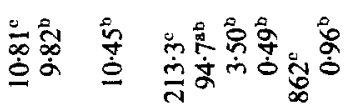

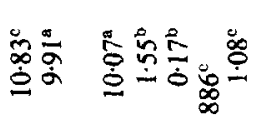

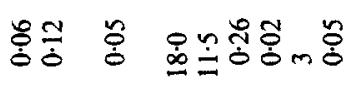

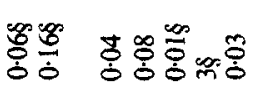

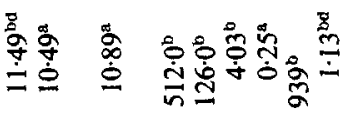

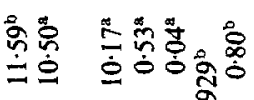

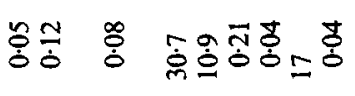

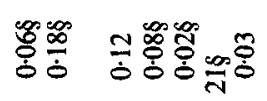

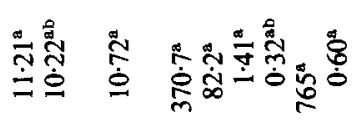

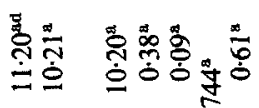<smiles>C1CCCC1</smiles>

要

\section{क्ष}

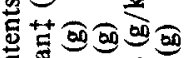

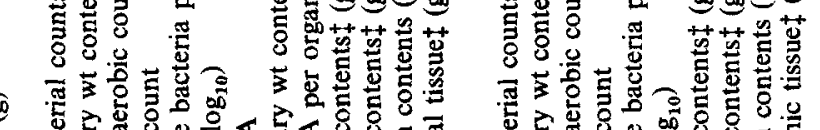

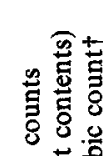

政国

(1)

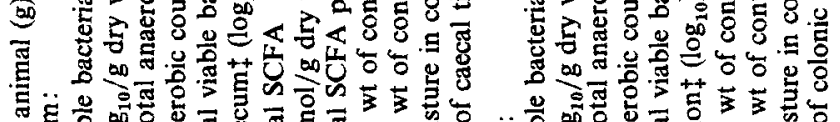

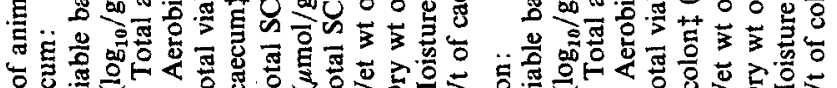

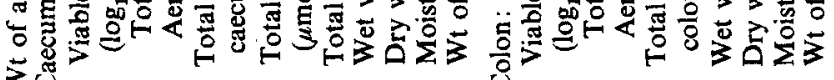

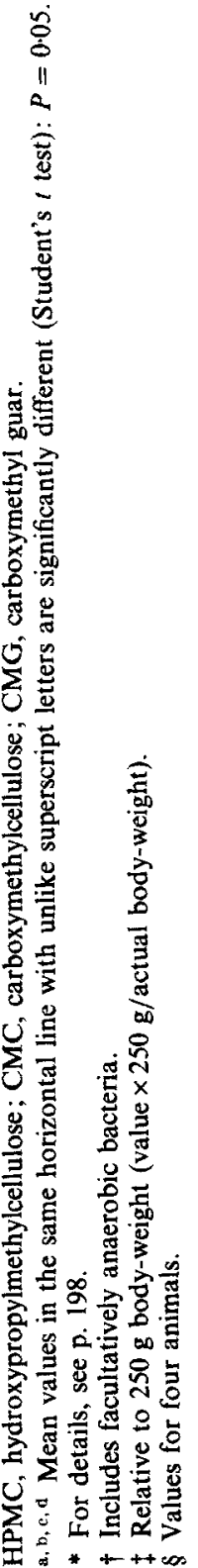


Table 2. The effect of non-digestible polysaccharides on wet weight and moisture content of faeces in rats

(Values are means with their standard errors for five animals per group)

\begin{tabular}{|c|c|c|c|c|c|}
\hline \multirow[b]{3}{*}{ Diet* } & \multicolumn{4}{|c|}{ Faecal output $(\mathrm{g} / 24 \mathrm{~h})$} & \multirow{3}{*}{$\begin{array}{c}\text { Moisture } \\
\text { content }(\mathrm{g} / \mathrm{kg})\end{array}$} \\
\hline & \multicolumn{2}{|c|}{ Wet } & \multicolumn{2}{|c|}{ Dry } & \\
\hline & Mean & $\mathbf{S E}$ & Mean & $\mathbf{S E}$ & \\
\hline FF & 1.23 & 0.13 & 0.79 & 0.06 & 355 \\
\hline Cellulose & $5 \cdot 22$ & 0.40 & 3.81 & 0.12 & 275 \\
\hline CMC & $13 \cdot 78$ & 2.43 & $3 \cdot 46$ & 0.60 & 747 \\
\hline HPMC & 11.59 & 0.99 & $3 \cdot 43$ & 0.14 & 702 \\
\hline Guar gum & 1.53 & 0.35 & 0.81 & 0.13 & 457 \\
\hline $\mathrm{CMG}$ & $7 \cdot 13$ & 0.71 & 2.96 & 0.29 & 588 \\
\hline Magnesium sulphate & 17.08 & $4 \cdot 25$ & 2.58 & 0.50 & 841 \\
\hline
\end{tabular}

FF, fibre free; CMC, carboxymethylcellulose; HPMC, hydroxypropylmethylcellulose; CMG, carboxymethyl guar.

* For details, see p. 198.

\section{RESULTS}

\section{Large-bowel morphology and contents}

The effects of HPMC, CMC and CMG on the weight, contents and microflora of the caecum and colon are compared with those of rats on a fibre-free diet in Table 1. The effect of a $\mathrm{MgSO}_{4}$-supplemented diet is also shown. Differences in the daily faecal output of animals given the test and control diets are shown in Table 2.

All the supplemented diets led to a visually obvious enlargement of the caecum, which was associated with increased wet weight of contents, and of tissue. As previously observed (Johnson \& Gee, 1986), the enlargement was particularly marked in the CMCsupplemented group, which had an almost eightfold increase in weight of caecal contents coupled with a doubling of tissue weight. The polysaccharides also significantly increased the dry weight of caecal contents. Similar increases in the colon contents and tissue weight occurred, but these were not always statistically significant.

Fig. 1 illustrates the relation between wet weight of caecal contents, and tissue mass in experiments in which the feeding period and polysaccharide supplement were varied. There was a strong correlation in both the caecum $(r 0.93)$ and colon $(r 0.94)$. No significant correlations were found between tissue weight and bacterial density, total number of bacteria per organ, moisture content, or SCFA concentration.

The animals fed on $\mathrm{CMC}$ - and $\mathrm{MgSO}_{4}$-containing diets developed diarrhoea (profuse unformed stools) from the 2 nd day of feeding, and the total output of faecal material was significantly increased (Table 2). The highest output of wet faecal material occurred in the $\mathrm{MgSO}_{4}$-fed rats, which also had the highest moisture content in caecal and colonic contents, and in the faecal material.

\section{Caeco-colonic microflora}

The density of bacteria in both the caecum and colon was increased by all the dietary treatments except HPMC and CMC; HPMC was associated with a significant reduction compared with the fibre-free controls (Table 1). The increased caecal mass in the animals fed on CMC and CMG led to their having considerably greater total bacterial numbers per caecum than the fibre-free controls. A markedly higher proportion of aerobic bacteria was 

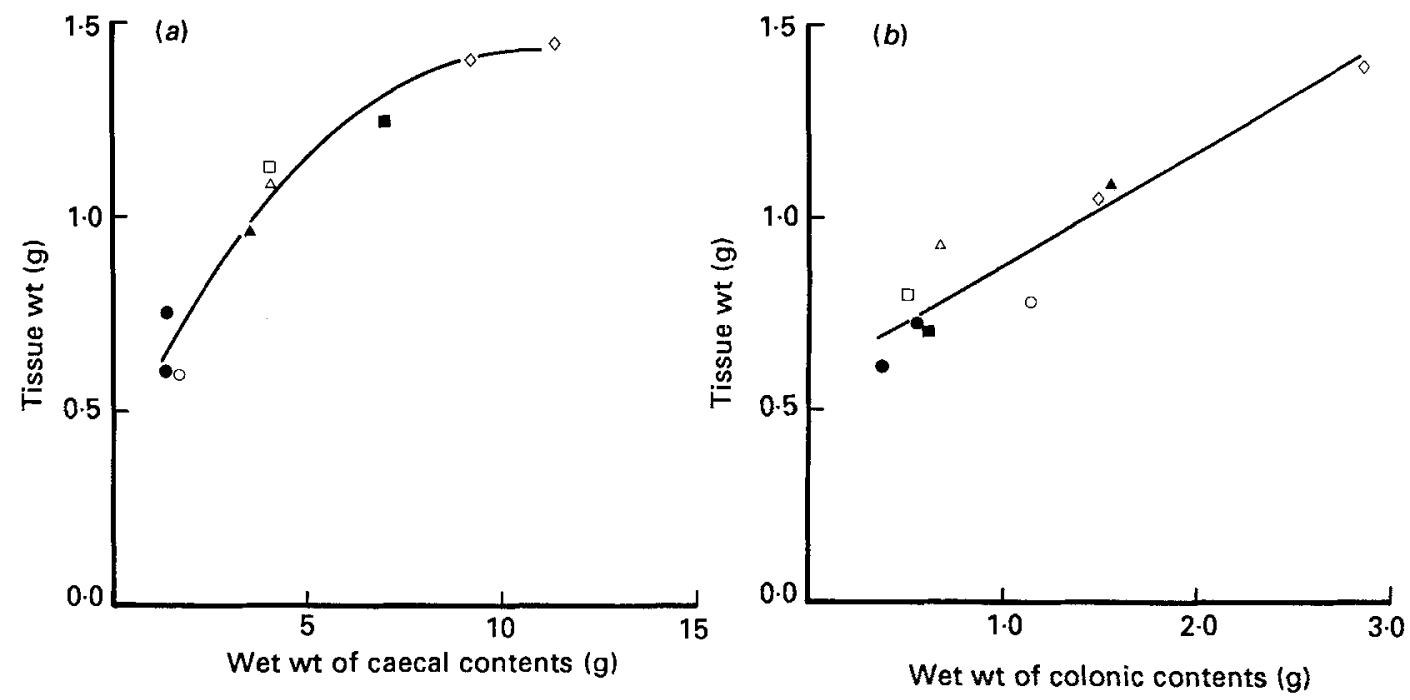

Fig. 1. The effect of weight of contents on $(a)$ caecal and $(b)$ colonic tissue weight in rats fed on diets containing non-digestible polysaccharides for $12 \mathrm{~d}$. Diets were fibre-free (O), hydroxypropylmethylcellulose (A), $\mathrm{MgSO}_{4}(\square)$, carboxymethyl guar $(\boldsymbol{\square})$ and carboxymethylcellulose $(\diamond)$; for details see p. 198. Each point is the mean of five animals. Additional points for fibre-free $(\bigcirc)$, guar gum $(\triangle)$, carboxymethylcellulose $(\diamond)$ and Solkafloc $(O)$ diets given for $7 \mathrm{~d}$ have been added to the $12 \mathrm{~d}$ feeding period values. Regression lines are fitted to the values:

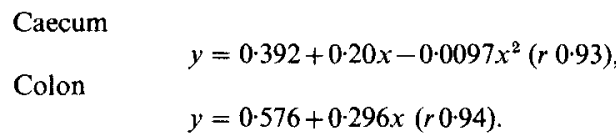

Table 3. Analysis of carbohydrate in intestinal contents of rats fed on fibre-free or carboxymethylcellulose- (CMC) supplemented diets*

(Values are means with their standard errors for five animals per group)

\begin{tabular}{|c|c|c|c|c|}
\hline & \multicolumn{2}{|c|}{ Ileum } & \multicolumn{2}{|c|}{ Colon } \\
\hline & Mean & $\mathrm{SE}$ & Mean & $\mathrm{SE}$ \\
\hline \multicolumn{5}{|c|}{$\begin{array}{l}\text { CMC in contents } \\
(\mathrm{mg} / 20 \mathrm{mg} \text { dry contents })\end{array}$} \\
\hline CMC diet & $6 \cdot 63$ & $2 \cdot 75$ & 8.92 & 0.23 \\
\hline \multicolumn{5}{|c|}{$\begin{array}{l}\text { Free reducing ends in contents } \\
(\mathrm{mg} / 20 \mathrm{mg} \text { dry contents } \dagger)\end{array}$} \\
\hline Fibre-free diet & $0 \cdot 66$ & $0 \cdot 14$ & $0 \cdot 58$ & 0.09 \\
\hline $\mathrm{CMC}$ diet & 0.54 & $0 \cdot 10$ & 0.54 & 0.06 \\
\hline
\end{tabular}

found in both caecal and colonic contents of rats fed on CMC compared with other diets, and these were almost entirely E. coli ( $93 \%$ of isolates). In contrast, the aerobic flora of the fibre-free group was composed primarily of Streptococcus spp. (95-100\% of isolates). No enterotoxin activity was detected in $E$. coli strains isolated from CMC-fed rats with diarrhoea; serotyping showed the strains to be in groups $\mathrm{O} 54$ and $\mathrm{O} 24$ which are not serogroups which commonly cause diarrhoea in man (Gross, 1983). 

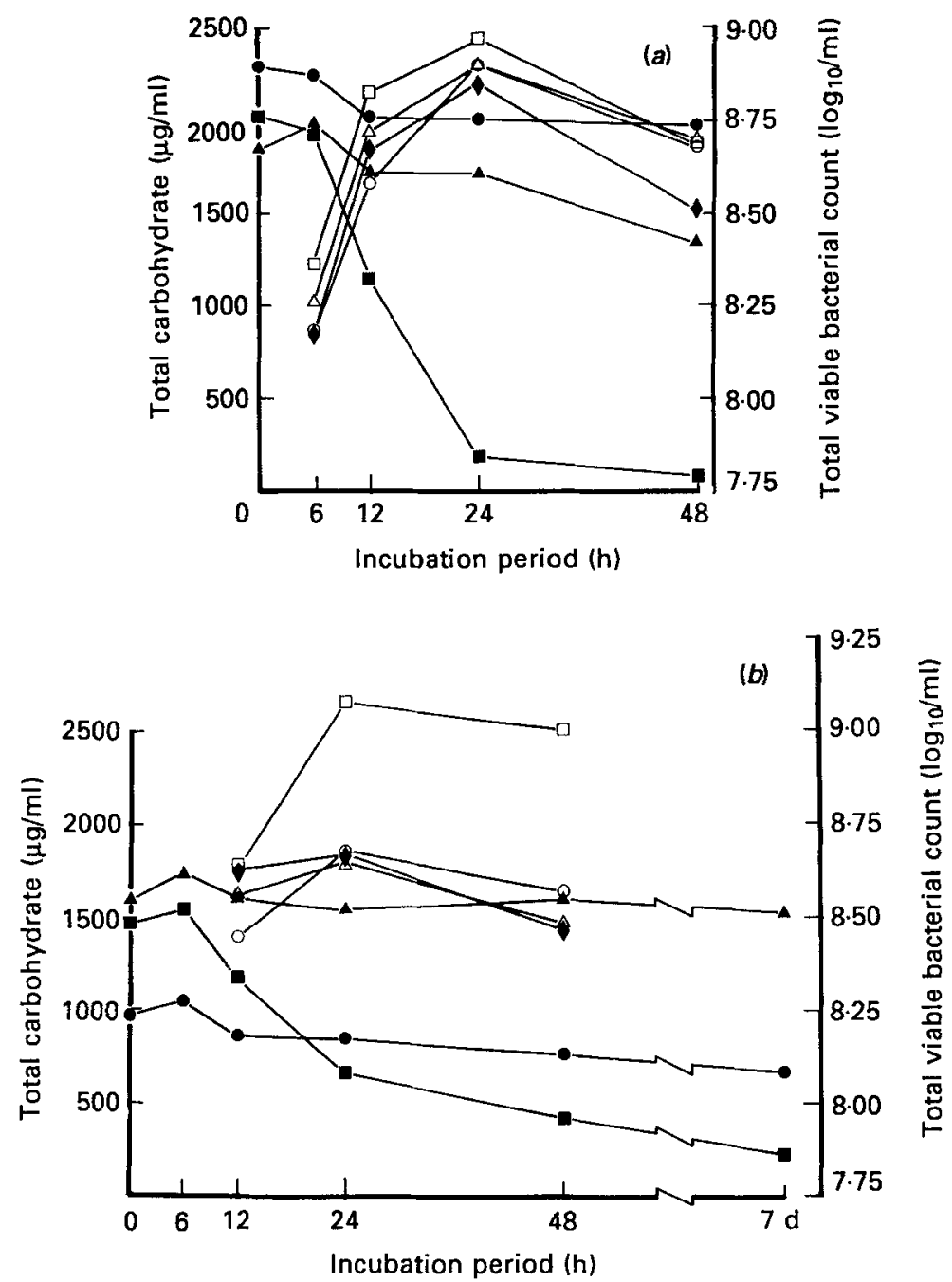

Fig. 2. Carbohydrate utilization (closed symbols) and bacterial growth (open symbols) in vitro. (a) BSM 10 broth alone $(\diamond)$; BSM 10 broth with $(2.0 \mathrm{mg} / \mathrm{ml})$ guar gum $(\square)$, carboxymethylcellulose $(\odot)$ or Solkafloc $(\Delta)$; values are means for four broths. (b) BSM 10 broth alone $(\bullet)$; BSM 10 broth with $(2.0$ $\mathrm{mg} / \mathrm{ml}$ ) carboxymethyl guar ( $\boldsymbol{\square})$, carboxymethylcellulose $(\boldsymbol{O})$ or hydroxypropylmethylcellulose $(\boldsymbol{A})$; values are means for two broths. The values for total carbohydrate have been corrected for basal medium values.

\section{Intralumen SCFA levels}

The highest caecal concentration of total SCFA was found in animals fed on the $\mathrm{MgSO}_{4}$ diet and these also had the lowest caecal dry weight content. The lowest SCFA concentrations occurred in those fed on CMC and HPMC diets. In contrast, the highest total per organ was found with the CMC and CMG diets, reflecting the higher weight of caecal contents in these animals (Table 1).

\section{Intralumen degradation of CMC}

A substantial amount of unfermented CMC was present in the intestinal contents of the rats fed on the CMC diet, and the proportion of CMC increased distally. The CMC 
Table 4. Measurement of free reducing-ends* in fiuid from caecal bacterial cultures containing hydroxypropylmethylcellulose (HPMC), carboxymethyl guar (CMG) or carboxymethylcellulose (CMC)

\begin{tabular}{cccc}
\hline & \multicolumn{3}{c}{ Substrate } \\
\cline { 2 - 4 } $\begin{array}{l}\text { Incubation } \\
\text { period (h) }\end{array}$ & HPMC & CMG & CMC \\
\hline 0 & 210 & 170 & 0 \\
6 & 150 & 140 & 0 \\
12 & 160 & 270 & 0 \\
24 & 140 & 250 & 0 \\
48 & 220 & 280 & 0 \\
$7 \mathrm{~d}$ & 150 & 230 & 50 \\
\hline
\end{tabular}

* $\mu \mathrm{g} / \mathrm{ml}$ glucose equivalents, values adjusted for basal medium control.

appeared not to have been hydrolysed to shorter chain lengths, as no increase in reducing ends could be demonstrated compared with the fibre-free diet, and there was no change in reducing-end concentration down the length of the intestine (Table 3).

\section{Intracaecal $p H$}

The mean $\mathrm{pH}$ of the caecal contents of rats fed on CMC (6.65, SE 0.10) did not differ significantly from that of rats fed on SF (6.75, SE 0.08). In contrast the caecal contents of rats given guar gum (pH 5.91, SE 0.13) were significantly more acidic than both the CMCand SF-fed groups $(P<0.01)$.

\section{In vitro degradation of the polysaccharides}

Fermentation of guar gum was rapid, with $95 \%$ of the polysaccharide being utilized after $24 \mathrm{~h}$ incubation at $37^{\circ}$ (Fig. 2(a)). Utilization of $\mathrm{CMG}$ was slower, with $28 \%$ remaining after $48 \mathrm{~h}$ incubation. Further incubation reduced this to $15 \%$ (Fig. 2(b)). CMC and SF were poorly fermented even after prolonged incubation, and HPMC remained almost completely unfermented, with only $5 \%$ of the substrate having been utilized after $7 \mathrm{~d}$ of incubation (Fig. 2). By $7 \mathrm{~d}$ of incubation there was only a very slight increase in the level of reducing-ends in the culture fluid with $\mathrm{CMC}$ as the substrate, but no significant change in reducing-ends for HPMC was recorded (Table 4); thus there appeared to be little or no degradation of these cellulose polymers. There was apparently a slight accumulation of reducing-ends with $\mathrm{CMG}$ as substrate and the final value was similar to the total measurable carbohydrate (Fig. 2(b)), suggesting that the carbohydrate residue after fermentation may have been composed of non-utilizable methylated monomers.

The total viable bacterial count of the broths immediately after inoculation was $\left(\log _{10} /\right.$ ml) 6.05 (Fig. $2(a)$ ) or 7.09 (Fig. 2(b)). Viable bacterial counts in the cultures after $24 \mathrm{~h}$ incubation were highest for guar gum and CMG (Fig. 2). Counts in SF cultures were slightly above those of the basal medium (Fig. 2(a)) and by $24 \mathrm{~h} \mathrm{CMC} \mathrm{counts} \mathrm{had} \mathrm{also}$ increased slightly above the basal value (Fig. 2). HPMC counts did not rise above those of the basal medium (Fig. 2(b)).

\section{WHC}

The WHC (g water/g organic matter) of the different polysaccharides was as follows (values are the means of duplicate analyses): CMC 12.8 (SE 0.3); CMG 10.2 (SE 0.8); HPMC 6.6 (SE 1.8); SF 2.1 (SE 0.8). These results do not support the findings of McBurney et al. (1985) that fibres with the highest WHC were also the most fermentable. 


\section{DISCUSSION}

In the present study, the addition of non-digestible polysaccharides to a basal, fibre-free rat diet led to a considerable enlargement of the caecum and colon. As in earlier experiments, the effect was most marked in the case of CMC, a material which we have previously shown to be associated with a particularly high rate of mucosal cell proliferation in the mid-and distal small intestine (Johnson \& Gee, 1986).

In several recent studies by other authors it has been reported that fermentable polysaccharides cause marked caecal enlargement associated with an increase in mucosal cell proliferation, and it has been argued that this is due to increased bacterial metabolism leading to a reduction in intralumen $\mathrm{pH}$ (Lupton et al. 1985), or a direct stimulatory effect of SCFA which Sakata (1987) regards as specific lumen trophic factors. This hypothesis is not supported by the present study since CMC was not significantly degraded during passage through the large bowel nor during prolonged incubation with faecal microflora in vitro, nor did it increase the density of bacteria in either the caecal or colonic contents. The $\mathrm{pH}$ of caecal contents for rats fed on $\mathrm{CMC}$, compared with the highly fermentable guar gum, confirms that CMC was not fermented in vivo. The concentration of SCFA was lowest in the CMC-fed animals, although the enlargement of their caeca and the retention of solids and fluid led to their having the highest total load of SCFA per organ. Conning et al. (1983) reported an increase in the activity per caecum of several enzymes in rats fed on CMC, and concluded that the $\beta 1 \rightarrow 4$-glucose backbone of CMC was readily assimilated by the gut flora. It would appear, however, that the increase in $\beta$-glucosidase activity per caecum could be accounted for by the increase in contents, which they also found.

When the mass of caecal contents was varied by altering the type, dietary level and duration of intake of dietary polysaccharides, there was a strong correlation between wet weight of caecal contents and tissue weight, suggesting that caecal and colonic enlargement may be a simple adaptive response to increased bulk of contents, whatever their nature. Such a mechanism may also account for the enlarged caeca found in germ-free rats where undigested mucus and food residues are known to accumulate.

Rather surprisingly, the concentration of SCFA in caecal contents was highest for the $\mathrm{MgSO}_{4}$ diet, partly perhaps because of the low retention of dry material in the caeca of these animals. SCFA concentrations in general did not parallel the density of bacteria, confirming our previous view that bacterial metabolism, or the rate at which SCFA are absorbed, may be modified by dietary consitutents other than fermentable polysaccharides (Horn et al. 1986).

Diarrhoea in rats fed on non-digestible polysaccharides appears not to be linked entirely to the moisture content of the faeces; CMC and HPMC diets gave faeces with similar moisture content, yet the stools of CMC-fed animals were poorly formed whilst those of the HPMC-fed animals were bulky, well formed pellets. Similar results were found with CMC and sodium alginate (Gohl \& Gohl, 1977), and with hydroxypropyl distarch phosphate (HDP) and tapioca starch (Wang, 1979). In each case both polysaccharides led to a high moisture content in the faeces or in the caecal contents, but only CMC or HDP caused diarrhoea. Diarrhoea did not occur in human volunteers consuming $15 \mathrm{~g} \mathrm{CMC} / \mathrm{d}$, which would presumably have been about $2-3 \%$ of their intake of dry matter (Anderson et al. 1986). The reason for the onset of diarrhoea in CMC-fed animals in the present study remains unclear. It may reflect the form of bound water and the physical or chemical properties of the polysaccharide in the faeces or it may have resulted from differences in motility. These possibilities are not of course mutually exclusive.

The bacterial populations of the caecum and colon varied significantly with diet. CMG gave the largest population in the present study, as did guar gum in our previous work 
(Horn et al. 1986). HPMC, like insoluble microcrystalline cellulose in our previous study, led to a reduced density of bacteria in caecal contents compared with that of animals given the fibre-free diet. This was not due to a diluting effect of undigested polysaccharide (Mallet et al. 1983), as the dry weight of contents was not increased and therefore the total number of bacteria in the caecum was also significantly lower on these diets.

The differences between the aerobic bacterial populations on the different diets were notable, but the significance of this finding is not known. Bruns et al. (1977) also found marked differences in the caecal aerobic flora with diet, with higher counts of lactobacilli and lower counts of streptococci on diets containing unmodified starch compared with diets containing hydroxypropyl starch. Gorbach (1971) pointed out that reductions in faecal anaerobes can occur as a consequence of diarrhoea. The animals given a $\mathrm{MgSO}_{4}-$ supplemented diet also developed diarrhoea of similar severity to that seen in the rats given $\mathrm{CMC}$, but there was no significant increase in the proportion of aerobes in these animals, nor in those given CMG, another carboxymethylated compound. The high proportion of aerobes, which proved to be almost entirely $E$. coli, in both the caecum and colon of the $\mathrm{CMC}$-fed rats raised the possibility that the diarrhoea could have been due to enterotoxigenic strains of this organism, but we obtained no evidence to support this hypothesis.

The present study establishes that the enlargement of the rat caecum in response to nondigestible polysaccharides can occur in situations where the polysaccharide is resistant to fermentation and therefore does not provide a substrate for bacterial metabolism. The adaptive response is not therefore primarily a response to bacterial fermentation. Hence, despite the striking ability of SCFA to stimulate mucosal cell proliferation (Sakata, 1987), the importance of this effect as a hypertrophic stimulus causing enlargement of gastrointestinal organs is doubtful. A possible alternative explanation is that the caecum enlarges to accommodate the tendency of residual material to accumulate within it, and this is governed by the pattern of motility and bulk flow through the whole large bowel. This, in turn, may depend primarily on the physical properties of the undigested residue, such as water retention and viscosity, both of which are relatively high in the modified cellulose gums. Even so there were important differences in the physical forms of stools produced by the two modified cellulose gums in the present study, and the reasons for this remain unclear. It is important that these effects should be explored in man, since modified cellulose gums are widely used as bulk laxatives and apparently minor differences in their chemical structure may have important clinical implications.

The authors would like to thank D. B. Archer for helpful discussions, Meyhall Chemical Co. for the gift of carboxymethyl guar and the MAFF Central Veterinary Laboratory, Weybridge for the enterotoxin assays.

\section{REFERENCES}

Anderson, D. M. W., Eastwood, M. A. \& Brydon, W. G. (1986). Food Hydrocolloids 1, 37-44.

Barnes, E. M. \& Impey, C. S. (1974). Journal of Applied Bacteriology 37, 393-409.

Bayliss, C. E. \& Houston, A. P. (1985). Food Microbiology 2, 53-62.

Bruns, P., Hood, L. F. \& Seeley, H. W. (1977). Nutrition Reports International 15, 131-138.

Bryant, M. P. \& Burkey, L. A. (1953). Journal of Dairy Science 36, $205-217$.

Conning, D. M., Mallet, A. K. \& Nicklin, S. (1983). In Gums and Stabilisers in the Food Industry vol. 2 ; Applications of Hydrocolloids, pp. 394-395 [G. D. Phillips, D. J. Wedlock and P. A. Williams, editors] Oxford: Pergamon Press.

Cowan, S. T. (1974). Cowan \& Steel's Manual for the Identification of Medical Bacteria. Cambridge: Cambridge University Press.

Dowling, R. H., Riecken, E. O., Laws, J. W. \& Booth, C. C. (1967). Clinical Science 32, 1-9. 
Dubois, M., Gilles, K. A., Hamilton, J. K., Rebers, P. A. \& Smith, F. (1956). Analytical Chemistry 28, $350-356$.

Dygert, S., Li, L. H., Florida, D. \& Thomas, J. A. (1965). Analytical Biochemistry 13, 367-374.

El-Harith, E. A., Dickerson, J. W. T. \& Walker, R. (1976). Food and Cosmetic Toxicology 14, 115-121.

El-Harith, E. A., Walker, R., Birch, G. G. \& Sukan, G. (1977). Food Chemistry 2, 279-289.

Elsenhans, B., Blume, R. \& Caspary, W. F. (1981). American Journal of Clinical Nutrition 34, 1837-1848.

Faulks, R. M. \& Timms, S. B. (1985). Food Chemistry 17, 273-287.

Gohl, B. \& Gohl, I. (1977). Journal of the Science of Food and Agriculture 28, 911-915.

Gorbach, S. L. (1971). Gastroenterology 60, 1110-1129.

Gross, R. J. (1983). Journal of Infection 7, 177-192.

Horn, N., Wyatt, G. M., Bayliss, C. E., Gee, J. M. \& Johnson, I. T. (1986). Food Microbiology 3, $295-302$.

Hungate, R. E. (1969). In Methods in Microbiology, vol. 3B, pp. 117-132 [J. R. Norris and D. W. Ribbons, editors]. London: Academic Press.

Jacobs, L. R. \& Lupton, J. R. (1984), American Journal of Physiology 246, G378-G385.

Johnson, I. T. \& Gee, J. M. (1986). British Journal of Nutrition 55, 497-505.

Johnson, I. T., Gee, J. M. \& Mahoney, R. R. (1984). British Journal of Nutrition 52, 477-487.

Konishi, F., Shidoji, Y., Oku, T. \& Hosuya, N. (1984). Japanese Journal of Experimental Medicine 54, $139-142$.

Leegwater, D. C., De Groot, A. P. \& van Kalmthout-Kuyper, M. (1974). Food and Cosmetic Toxicology 12, $687-697$.

Lupton, J. R., Coder, D. M. \& Jacobs, L. R. (1985). American Journal of Physiology 249, G382-G388.

McBurney, M. I., Horvath, P. J., Jeraci, J. L. \& van Soest, P. J. (1985). British Journal of Nutrition 53, $17-24$.

Mallet, A. K., Wise, A. \& Rowland, I. R. (1983). Archives of Toxicology 52, 311-317.

Rowland, I. R. \& Walker, R. (1983). In Toxic Hazards in Food, pp. 246-248 [D. M. Conning and A. B. G. Lansdown, editors]. London: Croom Helm.

Sakata, T. (1986). Journal of Nutrition Science and Vitaminology 32, 355-362.

Sakata, T. (1987). British Journal of Nutrition 58, 95-103.

Scotland, S. M., Gross, R. J. \& Rowe, B. (1985). In The Virulence of Escherichia coli, pp. 395-405 [M. Sussman, editor], London: Academic Press.

Southon, S., Gee, J. M. \& Johnson, I. T. (1987). British Journal of Nutrition 58, 65-72.

Wang, C. (1979). Effect of chemically-modified starch and unmodified tapioca starch on the caecum and colon of the rat. PhD Thesis, Cornell University. 